\title{
CREATING A CULTURE: PITCHFORK MEDIA'S TEXTUAL AND CULTURAL IMPACT ON ROLLING STONE MAGAZINE
}

\author{
Emily Brasher
}

Dr. Stephanie Craft, Thesis Supervisor

\begin{abstract}
The main purpose of this research is to demonstrate how cultures and subcultures can be created and disseminated through media, and how newer forms of media such as websites can have a tangible effect on the content of older forms of media such as print magazines. Specifically, this study uses the qualitative research methods of textual analysis and case study to explore how the music criticism website Pitchforkmedia.com creates and disseminates cultural capital in the form of "indie" music, and how this cultural capital is then reflected in the content of Rolling Stone magazine. A case study of the band Arcade Fire and its rise to the cultural mainstream demonstrates how Pitchfork can directly influence music culture and popularity; as well as how Pitchfork's editorial choices are reflected by Rolling Stone magazine. A textual analysis of annual “Top 50” lists from Pitchfork and Rolling Stone reveals Rolling Stone's implementation of the descriptor and label "indie" in its content a significant amount of time after Pitchfork thrust "indie" bands to the forefront of its editorial content. Through case study and textual analysis, filtered through the theoretical constructs of cultural theory, this research supports the hypothesis that Pitchfork could influence the editorial content of Rolling Stone.
\end{abstract}

